\title{
THE EFFECT OF Bi ADDITIVES ON THE PROPERTIES OF Fe-Pt FILMS
}

\author{
V.F. Bashev, N.A. Kutseva, O.I. Kushnerov, S.I. Ryabtsev*, O.V. Yelina, O.O. Veres \\ Oles Honchar Dnipro National University, Dnipro, Ukraine \\ *e-mail: sirybts@gmail.com
}

\begin{abstract}
Using the modernized three-electrode ion-plasma sputtering method, homogeneous thin films of FePt and $\mathrm{Fe}(\mathrm{Pt} / \mathrm{Bi})$ were obtained. Films were deposited on $\mathrm{NaCl}$ and glass-ceramic substrates. The film thickness was $120-530 \mathrm{~nm}$. In this case, the calculated cooling rate reached $\sim 10^{12}-10^{14} \mathrm{~K} / \mathrm{s}$. The structure of the $\mathrm{FePt}$ and $\mathrm{Fe}(\mathrm{Pt} / \mathrm{Bi})$ films was investigated using $\mathrm{X}$-ray diffraction and electron microscopy methods. It was established that metastable phases were formed in freshly sputtered films, including a supersaturated solid solution, a nanocrystalline and amorphous phases. It was determined that the obtained metastable structures are stable when heated to 540-880 K, depending on the composition. It was established that Bi additives significantly reduce the coercive force of films in the as-sputtered state. It was shown that a heat treatment increased the coercive force up to $36 \mathrm{kA} / \mathrm{m}$ in $\mathrm{FePt}$ films and up to $10 \mathrm{kA} / \mathrm{m}$ in $\mathrm{Fe}(\mathrm{Pt} / \mathrm{Bi})$ films. The composition of $\mathrm{Fe}(\mathrm{Pt} / \mathrm{Bi})$ films with a small value of the temperature coefficient of resistance (TCR $3 \cdot 10^{-5} \mathrm{~K}^{-1}$ ) was determined. phases.

Key words: thin film, ion-plasma sputtering, coercive force, metastable state, amorphous and crystalline
\end{abstract}

Received 11.11.2019; Received in revised form 19.12.2019; Accepted 23.12.2019

\section{Introduction}

One of the ways to increase the coercive force and magnetic energy of materials can be grinding the domain structure and creating thin diamagnetic layers between the domains. Attempts to such targeted control of the structure in thin film materials are known from the literature $[1,2]$. Potentially attractive alloys with improved magnetic properties include a large group of thin-film alloys that contain both ferromagnetic elements $(\mathrm{Co}, \mathrm{Ni}, \mathrm{Fe})$ and paramagnetic elements, for example, $\mathrm{Mg}, \mathrm{Pt}$, etc.

Investigations are known [3-7] devoted to the study of the effect of paramagnetic and diamagnetic additives, such as $\mathrm{Mg}, \mathrm{Pt}, \mathrm{Bi}, \mathrm{Ag}$, which practically do not mix with iron even in a liquid state, on the magnetic properties of iron. Such alloys can be obtained in the form of films by the method of modernized three-electrode ion-plasma sputtering (MTIPS) [3, 8]. The modernized method of three-electrode ion-plasma sputtering of mosaic targets [9] increases the efficiency of ion-plasma deposition methods and provides an increase in the kinetic energy of atoms sputtered from the target to $100-200 \mathrm{eV}$ before collision with the substrate [10]. This is 5-6 times more than with traditional methods of ion-plasma sputtering [11]. The cooling rates for the deposited films, theoretically estimated considering the atomic relaxation time, are in the range from $10^{12}$ to $10^{14} \mathrm{~K} / \mathrm{s}$. Thus, the structure of the films is formed under additional nonequilibrium conditions, and we can talk about quenching from the vapor state. Using the MTIPS method, homogeneous structures based on FePt and FePtBi alloys can be obtained. These alloys are very promising because they have high energy of uniaxial anisotropy and high coercive force. An interest in studying the compounds of this alloy with the addition of diamagnetic $\mathrm{Bi}$ is also caused by the fact that such a compound can combine the properties of soft magnetic and hard magnetic materials and opens up the possibility of a wide variety of applications.

The purpose of this study is to obtain homogeneous films of FePt and $\mathrm{Fe}(\mathrm{Pt} / \mathrm{Bi}$ ) alloys by the method of modernized three-electrode ion-plasma sputtering and to determine the effect of doping with diamagnetic Bi on the structure and properties of sprayed coating.

\section{Experimental procedure}

The objects of study were films of alloys of the following compositions (at.\%): $\mathrm{Fe}$ 20\%Pt; Fe-40\% Pt; Pt-27\% Fe; Pt-20\% Fe; Fe-20\% (Pt/Bi) Fe-29\% (Pt/Bi) Fe-36\%(Pt/Bi). 
The deposition of the films was carried out simultaneously on a glass ceramic substrate and on fresh chips of $\mathrm{NaCl}$ single crystals by the method of modernized threeelectrode ion-plasma sputtering (MTIPS) of typesetting targets [3,8].

The composition of the films was chosen considering information on the concentration range of the existence of equilibrium phases in $\mathrm{Fe}-\mathrm{Pt}, \mathrm{Fe}-\mathrm{Bi}$, and $\mathrm{Bi}-\mathrm{Pt}$ alloys [12]. Targets - parallelepipeds in the form of 16 cells, separated by barriers with the function of electrostatic lenses, were made from pure elements (not less than 99,99\%). The thickness of the obtained films was $120-530 \mathrm{~nm}$.

The content of elements in the films was estimated with an accuracy of $0,5 \%$ (at.) by a technique that considers the relationship between the relative area of the substrate occupied by the element and its content in the deposited film [9]. After salt separation, the phase composition of the films was studied in freshly sprayed and heat-treated states.

We used electron microscopy methods on an EMMA-2U device, and X-ray diffraction analysis on an URS-2.0 device. Physical properties and thermal stability were studied on films deposited on glass-metal substrates.

The electrical resistance of the films was measured by the four-probe method with continuous heating in vacuum of $\sim 10 \mathrm{mPa}$ with controlled heating rates from 4 to 18 $\mathrm{K} / \mathrm{min}$.

The magnetic properties were studied using a vibromagnetometer in a maximum magnetizing field of $0,3 \mathrm{~T}$, oriented parallel and perpendicular to the film surface.

\section{Results and discussion}

$\mathrm{Fe}-\mathrm{Pt}$ alloys in equilibrium correspond to the type of diagrams with an open $\gamma$ phase region. According to this diagram, the ordered $\mathrm{Fe}_{3} \mathrm{Pt}\left(\gamma_{1}\right)$ phase should be formed in the $\mathrm{Fe}-20 \% \mathrm{Pt}$ alloy at $1013 \mathrm{~K}$, the $\mathrm{FePt}\left(\gamma_{2}\right)$ phase - at $1573 \mathrm{~K}$ in the $\mathrm{Fe}-40 \% \mathrm{Pt}$ alloy, and the $\mathrm{FePt}_{3}\left(\gamma_{3}\right)$ phase - at $1623 \mathrm{~K}$ in the $\mathrm{Pt}-20 \ldots 36 \% \mathrm{Fe}$ alloy with the following regions of homogeneity: $\gamma_{1}-19-33$ at.\% $\mathrm{Pt}, \gamma_{2}-35-59$ at.\% $\mathrm{Pt}, \gamma_{3}-59-83$ at.\% $\mathrm{Pt}$ at 873 $\mathrm{K}$. After quenching from the vapor state, the phase composition of freshly sputtering films was characterized by the formation of an amorphous phase in the $\mathrm{Fe}-20 \% \mathrm{Pt}$ film.

In Fe $+40 \%$ Pt films, a dispersed solid solution of FePt is formed in the freshly sprayed state. After heating to a temperature of $903 \mathrm{~K}$ and cooling, coarsening of the structure is observed; the lattice period of the FePt solid solution remains practically unchanged. In $\mathrm{Fe}-70 \ldots 80 \% \mathrm{Pt}$ films, as shown by electron diffraction and X-ray studies (Fig. 1), in the initial state, a dispersed supersaturated solid solution based on Pt is formed with a lattice period of the solid solution different from the equilibrium value $(a=0,3937$ $\mathrm{nm}$ and $a=0,3985 \mathrm{~nm}$, respectively). This is evidenced by blurry lines in radiographs. After heating to $823 \mathrm{~K}$, the values of the lattice period of the solid solution take equilibrium values ( $a=0,3906 \mathrm{~nm}$ and $a=0,3873 \mathrm{~nm}$, respectively). Kurnakov phase formation in the studied films is not fixed.

A nanocrystalline phase was observed in the as-sputtered FePtBi films (with the size of the coherent scattering region $\mathrm{L} \sim 4-2,8 \mathrm{~nm}$ ). After heating in vacuum to $770-780 \mathrm{~K}$, a $10 \%$ increase in the region of coherent scattering of the nanocrystalline phase is observed; traces of cubic Bi and fcc solid solutions of FePt appear $(a=0,3769-0,377 \mathrm{~nm})$.

The boundaries of thermal stability of the obtained metastable structures are established. The thermal stability to structural transformations in FePt alloys decreases from $880 \mathrm{~K}$ in $\mathrm{Fe}+20$ at.\% Pt films to $670 \mathrm{~K}$ in $\mathrm{Fe}+40$ at.\% Pt films. In PtFe alloys, thermal stability decreases from $760 \mathrm{~K}$ to $750 \mathrm{~K}$ with an increase of the $\mathrm{Fe}$ content from 20 at. $\%$ to 27 at. $\%$. 


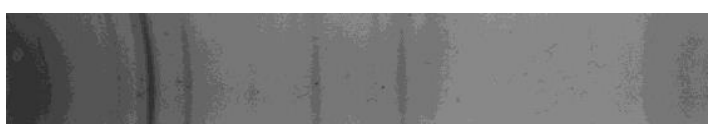

a)

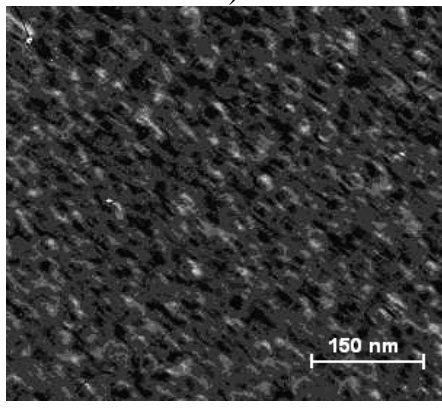

c)

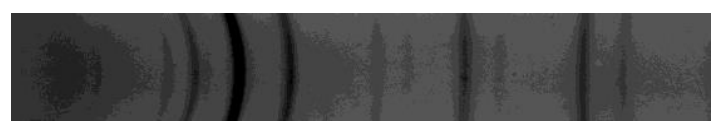

b)

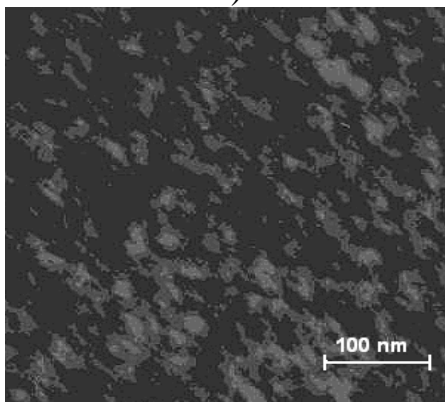

d)

Fig. 1. The results of $\mathrm{X}$-ray and electron diffraction investigation of the Pt-30\% Fe film: a), c) the as-sputtered state, and b), d) after heating to $823 \mathrm{~K}$.

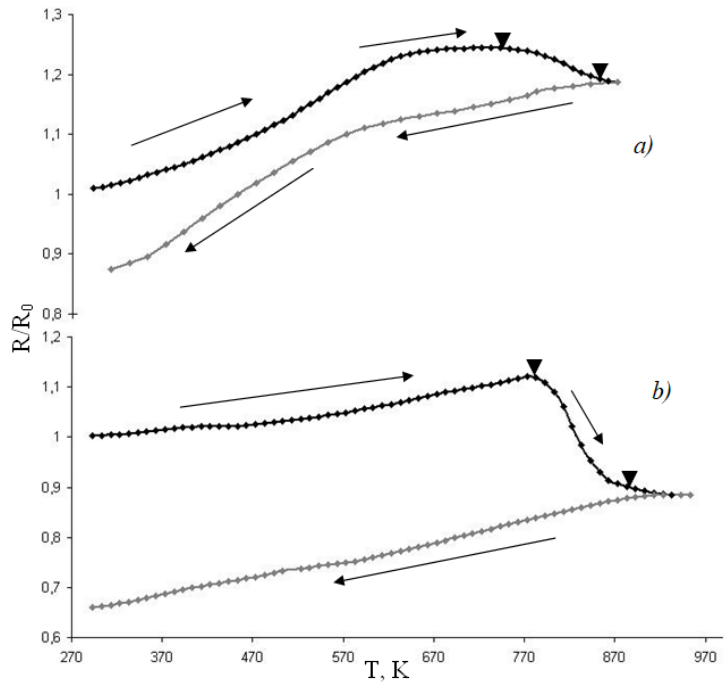

Fig 2. Dependence of film resistance on heating temperature: a) $\mathrm{Fe}_{80} \mathrm{Pt}_{20}$; b) $\mathrm{Fe}_{20} \mathrm{Pt}_{80}$.

The temperature coefficient of resistance (TCR) of films in the freshly sprayed state varies from $0.4 \cdot 10^{-4}$ to $18,8 \cdot 10^{-4} \mathrm{~K}^{-1}$ depending on the Pt content. The minimum TCR value is considered in the alloy $\mathrm{Pt}-27 \% \mathrm{Fe}$. Additives of Bi reduce the temperature of the onset of phase transformations and structural changes of $\mathrm{Fe}-(\mathrm{Pt} / \mathrm{Bi})$ films to $540-550 \mathrm{~K}$, TCR of $\mathrm{Fe}-29 . . .36 \%$ (Pt/Bi) films goes into the negative region. In $\mathrm{Fe}_{80} \mathrm{Pt}_{11} \mathrm{Bi}_{9}$ films with a lower Bi content, a low TCR $3 \cdot 10^{-5} \mathrm{~K}^{-1}$ in the initial state was obtained. Fe-Pt films are characterized by anisotropy of magnetic properties. With the perpendicular orientation of the magnetic field, the films exhibit weak hysteresis properties. For freshly sprayed $\mathrm{Fe}-\mathrm{Pt}$ films, with an increase of the Pt content, the coercive force increases from $5 \mathrm{kA} / \mathrm{m}$ to 7 $\mathrm{kA} / \mathrm{m}$. After heating the films in vacuum to $770-780 \mathrm{~K}$, the coercive force increases by more than 10 times, reaching $36 \mathrm{kA} / \mathrm{m}$ in Fe-40\% Pt films. Films Fe-29... 36\% (Pt/Bi) do not show magnetization hysteresis in parallel and perpendicular fields. A decrease of the $\left(\mathrm{Pt} / \mathrm{Bi}\right.$ ) content in $\mathrm{Fe}_{80} \mathrm{Pt}_{11} \mathrm{Bi}_{9}$ films after heating to $770 \mathrm{~K}$ leads to an increase of the coercive force from $0,2 \mathrm{kA} / \mathrm{m}$ to $10 \mathrm{kA} / \mathrm{m}$. Heating above this temperature leads to oxidation and a significant deterioration in magnetic properties. Thus, an improvement of magnetic characteristics can be implemented by choosing the exposure time at a given temperature. 


\section{Conclusions}

By quenching from a vapor state, potentially attractive alloys with improved magnetic properties are obtained. Thin films of $\mathrm{FePt}$ and $\mathrm{Fe}(\mathrm{Pt} / \mathrm{Bi})$ were obtained either with the structure of a supersaturated solid solution or in an amorphous or nanocrystalline state. By using X-ray diffraction and electron microscopy, the study of the structure and properties of $\mathrm{FePt}$ and $\mathrm{Fe}(\mathrm{Pt} / \mathrm{Bi})$ films in the freshly sprayed state and after heat treatment made it possible to establish the boundaries of the thermal stability of the obtained metastable structures. Heat treatment modes and compositions with a high coercive force (up to $36 \mathrm{kA} / \mathrm{m}$ ) and a low temperature coefficient of resistance (TCR $\sim 3 \cdot 10^{-5} \mathrm{~K}^{-1}$ ) are determined. The studied films are promising from the point of view of developing miniature magnets and devices for magnetic recording of high-density information.

\section{References}

1. Wan, H. Direct evidence of phase separation in as-deposited $\mathrm{Fe}(\mathrm{Co})-\mathrm{Ag}$ films with giant magnetoresistance / H. Wan, A. Tsoukatos, G.C. Hadjipanayis et al. / Phys. Rev. B. - 1994. - Vol. 49, No 2. - P.1524 - 1527.

2. Shpak, A.P. Phase composition and physical properties of high-carbon Fe-C films / A.P. Shpak, V.F. Bashev, G.P. Breharia, et al. // Metallofizika. Noveyshiye tekhnologii. - 2007. - Vol. 29, No. 10. - P. 1369 - 1381.

3. Ryabtsev, S.I. Structure and properties of ion-plasma-deposited films of $\mathrm{Fe}-$ (Ag,Bi) alloys / S.I. Ryabtsev // Phys. Met. Metallogr. - 2009. - Vol. 108, No. 3. - P. 226 -231 .

4. Bashev, V.F. Effect of nonequilibrium vapor deposition on phase composition and properties of $\mathrm{Fe}-\mathrm{Mg}$ films / V.F. Bashev, O.E. Beletskaya, Z.V. Balyuk, S.I. Ryabtsev. Physics of Metals and Metallography. - 2003. - Vol. 96, Issue 1. -P. 72 - 74.

5. Zhen, C. Effects of $\mathrm{C}$ layer on the microstructure and magnetic properties of FePt recording media films / C. Zhen,. X. Zhai, L. Ma, X. Li, Xiangfu Nie // Materials Science and Engineering B. - 2006. - Vol. 129. - P. 261 - 264.

6. Kuo, C.M. Magnetic properties and microstructure of FePt-Si3N4 nanocomposite thin films /C.M. Kuo, P.C. Kuo // Journal of Applied Physics. - 2000. Vol. 87, No 1. - P. 419 - 426.

7. Bian, B. Ordering of island-like FePt crystallites with orientations / K. Sato, Y. Hirotsu // Applied Physics Letters. - 1999. - Vol. 75, No. 23. - P. 3686 - 3688.

8. Bashev, V.F. Physical properties and structure of vapor-quenched immiscible alloys / V.F. Bashev, N.A. Kutseva, A.I. Kushnerov, et al. / Journal of Physics and Electronics. -2018. -Vol.26(1). - P. $45-52$.

9. Ryabtsev, S. Structure and Physical Properties of Ni Films in Metastable States / S. Ryabtsev, P. Gusevik, V. Bashev, F. Dotsenko / J. Mater. Sci. Eng. - 2012. - Vol. A2, No. 9. - P. $648-653$.

10. Dotsenko, F.F. Physical preconditions of non-equilibrium state formation and estimation of deposited alloys composition / F.F. Dotsenko, V.F. Bashev // Visnyk Dnipropetrovs'koho Universytetu. Seriya: Fizyka. Radioelectronika. - 2001. - Issue 7. P. 8 - 17 (in Russian).

11. Efremenko, V.G. Effect of bulk heat treatment and plasma surface hardening on the microstructure and erosion wear resistance of complex-alloyed cast irons with spheroidal vanadium carbides / V.G. Efremenko, K. Shimizu, T.V. Pastukhova, et al. // J. Friction Wear. - 2017. - Vol. 38, No. 1. - P. 58 - 64.

12. Phase diagrams of binary metal systems: Reference: in three volumes. Vol.2 / General editor N.P. Lyakisheva. - M.: Mashinostroyeniye, 1997. - 1024 p. (in Russian). 